\title{
Review
}

\section{JNK Regulation of Depression and Anxiety}

\author{
Patrik Hollos, Francesca Marchisella and Eleanor T. Coffey* \\ Turku Centre for Biotechnology, Åbo Akademi and University of Turku, BioCity, Turku FIN, Finland
}

\begin{abstract}
Depression and anxiety are the most common mood disorders affecting 300 million sufferers worldwide. Maladaptive changes in the neuroendocrine stress response is cited as the most common underlying cause, though how the circuits underlying this response are controlled at the molecular level, remains largely unknown. Approximately $40 \%$ of patients do not respond to current treatments, indicating that untapped mechanisms exist. Here we review recent evidence implicating JNK in the control of anxiety and depressive-like behavior with a particular focus on its action in immature granule cells of the hippocampal neurogenic niche and the potential for therapeutic targeting for affective disorders.
\end{abstract}

Keywords: JNK, XG-102, JNK1, kinase, anxiety, depression, granule cell, neurogenesis, hippocampus, molecular, mechanism

Anxiety and depression are among the largest causes of disability worldwide [1]. They have complex and varied etiologies with genetic, epigenetic and environmental factors contributing to disease susceptibility. Maladaptative changes in normal stress responses leading to long lasting physical changes at the level of synapses and circuits are believed to be among the underlying causes. Antidepressant drugs have targeted the same core mechanisms for several decades, yet treatment-resistant depression is still a major problem, indicating the need for a paradigm shift [2]. Many theories of depression have been proposed, including dysregulation of monoaminergic neurotransmission, neurotrophic factors and hippocampal neurogenesis [3, 4]. However, the signalling molecules that govern mood and its underlying circuitry are largely unknown and identifying these will be essential for a comprehensive understanding of mood disorders and development of new treatments.

\footnotetext{
${ }^{*}$ Correspondence to: Eleanor T. Coffey, Turku Centre for Biotechnology, Åbo Akademi and University of Turku, BioCity, Tykistokatu 6, Turku FIN-20520, Finland. Tel.: +358 40 1822424; E-mail: elecof@utu.fi.
}

\section{ADULT HIPPOCAMPAL NEUROGENESIS AND DEPRESSION}

Prominent studies have shown that adult hippocampal neurogenesis is required for the action of antidepressant drugs [5-8], as well as for electroconvulsive shock therapy [9]. This discovery prompted extensive studies of adult born hippocampal granule cells in the context of mood, leading to the hypothesis that depressive and anxiety symptoms can be alleviated by boosting neurogenesis in the hippocampus while impaired neurogenesis may be causal in triggering symptoms initially. Yet, this theory remains controversial as other studies have shown beneficial effects of antidepressants that were independent of neurogenesis changes $[10,11]$. Our lab identified that inhibition of c-Jun N-terminal kinase (JNK) in the hippocampal neurogenic niche increases the number of adult born granule cells, while alleviating anxiety behaviour [12]. More critically, we demonstrated that inhibiting JNK solely in adult born granule cells was sufficient to alleviate anxiety and depressive behavior [12]. These findings implicate JNK as a central player that controls anxiety and depression from 
a subpopulation of adult born granule cells in the hippocampus.

First described in the hippocampus [13], the generation of new neurons in adult brain, or "neurogenesis" occurs at a rate of about 700 new granule cells added daily per hippocampus in humans, representing $0.004 \%$ of dentate gyrus neurons [14]. Notably, adult hippocampal neurogenesis is confined to the dentate gyrus sub-region of the hippocampus in all species [15]. In rodents, the extent of neurogenesis in the dentate gyrus is higher [16], accounting for up to $0.06 \%$ of dentate gyrus granule cells in two month old mice $[17,18]$. Increased neurogenesis in the dorsal hippocampus has been shown to improve spatial memory $[19,20]$ whereas in the ventral hippocampus, it is associated with suppression of anxiety-like behaviour [7, 21-23]. Neurogenesis in mice can be boosted by exercise or by exposure to an enriched environment [17, 22, 24], leading to improved memory $[25,26]$. However, running induces neurogenesis in the dorsal and not the ventral hippocampus [27], and running-induced suppression of anxiety has been dissociated from hippocampal neurogenesis $[7,10,11,28]$.

\section{ANXIETY AND DEPRESSION - THE HIPPOCAMPAL CONNECTION}

Anxiety is a normal stress response that allows the individual to react to a threatening environment. Anxiety disorders arise when this stress response occurs in the absence of real threat. It shows a high level of comorbidity with depression and rates of secondary depression following a prior psychiatric illness, in particular anxiety, have grown significantly in modern times [29]. In depressed individuals, disease-associated structural changes take place in the hippocampus, indicating a central role for this region in the underlying pathology. Neuroimaging studies have suggested that hippocampal volume may be reduced in patients suffering from depression and anxiety [30, 31]. These findings from small patient cohorts have been validated by meta-analysis (involving 1728 major depressive disorder (MDD) patients and 7199 controls) and conclude that hippocampal volume decreases on average by $1.42 \%$ in MDD. Moreover, this decrease in hippocampal volume correlates with recurrence frequency [31]. Post-mortem studies in MDD subjects revealed loss of neuropil, i.e. neuritic matter consisting of unmyelinated axons, dendrites or glial cell processes, suggesting that neurite atrophy and synapse loss accounted for diminished volume in this region $[32,33]$. Specifically in the hippocampal Cornu Ammonis-3 (CA3) region, reduced dendrite and spine density was associated with higher levels of trait anxiety and longitudinal depression scores [34, 35], while in the dentate gyrus sub-region, the number of neural progenitor cells and granule cells was reduced in MDD subjects [36, 37]. While these anatomical hallmarks of MDD suggest that levels of adult hippocampal neurogenesis may be reduced in these individuals, definitive proof that neurogenesis is impaired in humans suffering from affective disorders is still lacking. This is because no studies have used birth dating approaches to study neurogenesis in post mortem brains from humans that suffered from these disorders. Also, there are currently no methods to directly measure neurogenesis in situ in humans.

Stereological measurement of neurogenesis in post mortem brain has provided some evidence for a link between depression and adult hippocampal neurogenesis. For example, depressed subjects that received selective serotonin reuptake inhibitor (SSRI) or tricyclic anti-depressant (TCA) drugs, showed increased neural progenitor number in the anterior (ventral) dentate gyrus compared to untreated subjects [36]. Another study showed that hippocampal volume was restored in patients that received antidepressant drugs [37]. Interestingly, the meta-analysis found no significant recovery of hippocampal volume in patients undergoing antidepressant treatment [31], possibly due to confounding interactions such as severity and duration of disease. Nonetheless, these clinical studies have provided clear evidence that structural changes occur at many levels in the hippocampus of individuals suffering from depression and anxiety and have given insight into the underlying pathology.

Similarly in animal models, the hippocampus emerges as a central regulator of depression and anxiety [38-42]. The ventral hippocampus extends connections to prefrontal cortex (PFC) [43] and forms reciprocal connections with amygdala [41], among other regions [44-46]. These circuits are highly conserved and are required for synchronized hippocampal-PFC activity and normal adaptive, anxiety behaviour [47]. Maladaptive changes in circuits emanating from the hippocampus are likely to contribute to the pathological state where anxiety is present in the absence of threat [48]. The signalling molecules driving these circuits and maladaptive changes therein are largely unknown. 


\section{C-JUN N-TERMINAL KINASES (JNKS)}

JNK was originally identified as stress-activated protein kinase (SAPK) that responded to a range of cellular stressors including DNA damage, oxidative stress, cytoskeletal toxins, infection and inflammation [49]. SAPK was renamed "JNK" when it was identified as the kinase responsible for phosphorylation and transcriptional activation of c-Jun [50, 51]. In brain, JNK expression is complex, with three JNK genes; JNK1 (MAPK8), JNK2 (MAPK9) and JNK3 (MAPK10) and 10 splice variants (JNK $1 \alpha 1, \mathrm{JNK} 1 \alpha 2$, JNK1 1 1, JNK1 $\beta 2$, JNK $2 \alpha 1$, JNK2 $\alpha 2$, JNK2 $\beta 1$, JNK2 $\beta 2$, JNK3 $\alpha 1, \mathrm{JNK} 3 \alpha 2$ ) being expressed [52]. JNKs are associated with inflammation, neurodegeneration and insulin resistance [53-55]. JNKs are particularly important kinases in brain where they display elevated activity in the absence of stress, indicating that brain JNKs also serve non-stress related functions. This distinguishes brain JNK from JNK in other tissues such as heart, lung, kidney, spleen and liver, where its activity is low in the absence of stress [56]. JNK1 constitutes a major component of physiologically active JNK in brain, whereas JNK2 and JNK3 isoforms exhibit lower basal activity and increased stress responsivity [57]. Yet, knockout or knockdown of all three JNK isoforms has been necessary to reveal functions for JNK in trophic deprivation-induced neuronal death [58], autophagy [59] and pituitary function [54] indicating functional redundancy between isoforms. JNK has also been shown to regulate neuropathic pain [60] and inhibition of JNK protects from neuronal death following cerebral ischemia [61, 62]. Interestingly however, with the exception of JNK regulation of pituitary function and insulin resistance $[63,64]$, until recently, there was relatively little known about the physiological role of JNK in adult brain based on in vivo study and behavioural analysis. Here we outline recent evidence that associates JNK with the control of mood.

\section{JNK1 REGULATES ANXIETY AND DEPRESSIVE-LIKE BEHAVIOUR IN MICE}

To gain insight on JNK1 function in adult brain, Jnkl-/-mice were subjected to a battery of behavioural tests. The most prominent results emerged from tests for anxiety where Jnkl -/- mice displayed a low anxiety phenotype in the open field, elevated plus maze and light-dark tests [12] (Table 1). In the forced swim test of behavioural despair and the sucrose deprivation test to determine anhedonic behaviour, Jnk1-/- mice displayed reduced immobility and reduced anhedonia respectively, indicating a low depressive phenotype [12] (Table 1). These behavioural phenotypes were replicated when mice underwent intracerebroventricular infusion for six weeks with a peptide inhibitor of JNK (DJNKI-1, chemically identical to XG-102) (Fig. 1A; Table 1) [12].

\section{JNK1 ACTIVITY IN NEWBORN GRANULE CELLS OF THE HIPPOCAMPUS INDUCES ANXIOGENIC AND DEPRESSIVE BEHAVIOR}

Changes in the rate of adult hippocampal neurogenesis have been implicated in the pathology of anxiety and depression $[3,65]$. We therefore examined neurogenesis in Jnkl knockout mice using birthdate labelling. These results showed that progenitor cell proliferation was increased in the dentate gyrus of mice lacking Jnk1 and that the number of adult born (BrdU/NeuN-positive) neurons was increased (Fig. 1B) [12]. Moreover, cell survival and dendrite maturation, as measured by arborisation, was elevated in Jnk1 knockout mice (Fig. 1B) [12]. Importantly, these effects were replicated upon mini-pump infusion to the ventricles with a peptide inhibitor of JNK1 for six weeks (Fig. 1B) [12]. Finally, to determine whether adult born granule cells themselves were involved in the anxiolytic response, we expressed the JNK inhibitor in a Murine Leukemia Virus (MLV) plasmid and injected it to the hilus. This enabled selective targeting of the JNK inhibitor to newly born granule cells in the hippocampus of adult mice [12]. To our surprise, JNK inhibition solely in these cells was sufficient to reduce anxiety and depressive behaviour, indicating that JNK activity in newborn granule cells of the hippocampus plays an important role in the regulation of mood. Notably, there was no increase in granule cell number in these mice. Thus, like others $[10,11]$, we showed that increased neurogenesis was not necessary for this behavioural switch, as inhibition of JNK in new born granule cells was sufficient to improve mood in mice without having any effect on number of immature granule cells (Fig. 1B) [12].

\section{THE DJNKI-1 INHIBITOR OF JNK}

To inhibit JNK, the peptide inhibitor of JNK, DJNKI-1 (also known as XG-102) was used. This 
is the minimal sequence from the JNK scaffold, JNK interacting protein-1 (JIP1) that binds to the common docking domain of JNK and competes for substrate binding [53, 66]. DJNKI-1 also encodes the transactivator of transcription (TAT) sequence from the HIV vector which facilitates cell penetration $[67,68]$. Further, to improve resilience against enzymatic digestion in vivo, DJNKI-1 utilizes D-amino acids, providing stability in cells for at least two weeks [69]. DJNKI-1 is considered to be a specific inhibitor of JNK and does not inhibit the closely related ERK or p38 kinases [70]. In our hands, DJNKI-1 more potently inhibits JNK1 isoforms over JNK2 and JNK3 in vitro (Coffey lab unpublished data), however its bioactivity against JNK isoforms in vivo has not been characterised. For this reason, it is significant that we cross-validated the findings with DJNKI-1 in Jnk1-/- mice.

Our lab has earlier shown that a longer version of the JNK inhibitor peptide, amino acids 1-277 of the JNK scaffold JIP1 (JBD for JNK binding domain), increased dendrite arborisation in cultured neurons, recapitulating findings in Jnkl-/- mice where dendrite arborisation was increased in the cerebellum and motor cortex [71, 72]. Thus, it was not altogether surprising that in adult hippocampus, JNK1 constrained the arborisation of doublecortin (DCX)positive, immature granule cells (Fig. 1B) [12]. Indeed inhibition of JNK1 proved to be a powerful stimulus for adult hippocampal neurogenesis, promoting all four stages: proliferation, survival, differentiation and maturation (Fig. 1B).

\section{HOW COULD JNK INHIBITION IN GRANULE CELLS ALTER BEHAVIOUR?}

Dentate gyrus granule cells form a major cell group of the hippocampal trisynaptic circuit. They receive excitatory input from the entorhinal cortex via perforant path axons and transmit this to CA3 pyramidal neurons via their mossy fibers. The circuit is completed by projections from $\mathrm{CA} 3$ to $\mathrm{CA} 1$ which projects back to the entorhinal cortex. Indeed, the immature granule cells of the hippocampus are particularly sensitive to perforant path input [73]. They display a lower activation threshold than resident granule cells due to their particular configuration that equips them with increased excitatory/inhibitory balance [73]. Significantly, immature granule cells negatively regulate the overall activity of resident dentate granule cells by recruiting local GABAergic inhibitory neurons $[42,73,74]$. Consistent with this, increasing neurogenesis in mice leads to reduced activity of the dentate gyrus hippocampal subregion $[42,74,75]$. Conversely, blocking neurogenesis using $x$-ray irradiation or chemical genetic ablation, increases dentate gyrus gamma burst amplitude and synchronized firing [76]. The ventral hippocampus forms direct monosynaptic connections to structures that regulate mood such as medial prefrontal cortex which promotes anxiety behaviour $[47,77]$, reciprocal connections to and from amygdala, which governs fear processing [78], and to the medial shell of the nucleus accumbens [79, 80] which controls reward seeking behaviour and susceptibility to stress [81]. Thus boosting the number of adult born granule cells, or increasing their activity, is expected to reduce the neural activity of glutamatergic projections from the ventral hippocampus to downstream structures that regulate anxiety and reward responses [42]. Indeed, it has recently been shown that excitatory output from the ventral hippocampus to the medial prefrontal cortex is required for anxious behavior [47], while reduced activity in this region is associated with stress resilience in the chronic social defeat model of depression [81]. One possibility is that JNK evokes anxiogenic behaviour by controlling properties of immature granule cells leading to

Table 1

Inhibition of JNK1 lowers anxiety and depressive behaviour in mice

\begin{tabular}{lccc}
\hline & $\begin{array}{c}\text { Jnkl-/ } \\
2-4 \text { months }\end{array}$ & $\begin{array}{c}\text { DJNKI-1 (XG-102) } \\
\text { 2-4 months }\end{array}$ & $\begin{array}{c}\text { MLV-NLS-JBD } \\
\text { 2-4 months }\end{array}$ \\
\cline { 2 - 4 } Behavioraltests & & Anxiety/depressivephenotype & \\
\hline EPM & $\downarrow$ & $\downarrow$ & $\downarrow$ \\
Light/Dark & $\downarrow$ & $\downarrow$ & $\downarrow$ \\
Open Field & $\downarrow$ & n.a. & $\downarrow$ \\
FST & $\downarrow$ & $\downarrow$ & $\downarrow$ \\
Anhedonia & $\downarrow$ & $\downarrow$ & $\downarrow$ \\
\hline
\end{tabular}

Summary of behavioural test results from Mohammad and colleagues [12]. DJNKI-1 refers to a peptide inhibitor of JNK, also known as XG-102. MLV-NLS-JBD encodes amino acids 1 to 277 of JIP1 in a MLV retroviral vector with upstream flanking nuclear localisation sequences (NLS). The JBD sequence effectively inhibits nuclear JNK in neurons [71, 107]. 
A

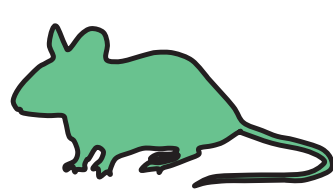

Jnk1-/- mice

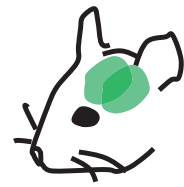

DJNKI-1 (XG-102) ICV delivery

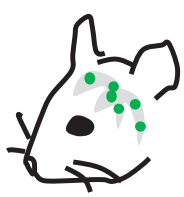

JNK inhibition in newborn GCs

Retroviral delivery of JNK inhibitor

All modes of JNK1 inhibition $\downarrow$

anxiety/depressive-like behavior

B

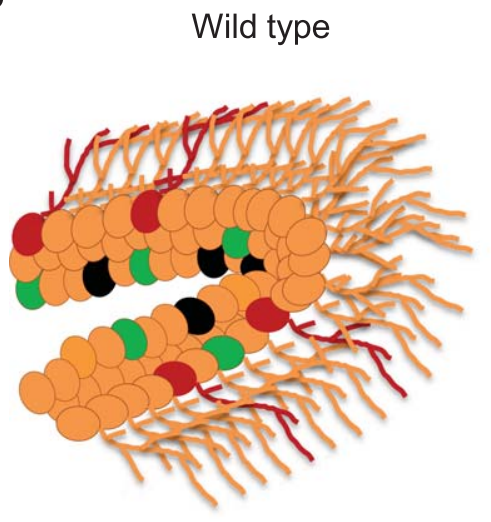

Jnk1 -/- or DJNKI-1 (XG-102)

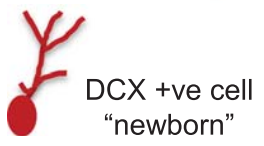

Cleaved caspase- 3 +ve cell "apoptotic"

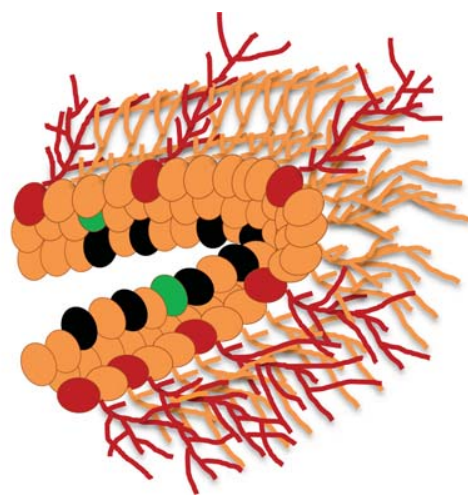

$\mathrm{BrdU} / \mathrm{NeuN}+$ ve cell "neurogenic"

Summary schemes based on data in Mohammad et al., 2016.

Fig. 1. Inhibition of JNK solely in newborn granule cells of the hippocampus alleviates anxiety and depressive behaviour whereas global inhibition of JNK1 in brain boosts neurogenesis. A. Genetic ablation of Jnk1, intracerebroventricular (ICV) osmotic mini-pump infusion of DJNKI-1 (XG-102) over six weeks, or retroviral delivery of JNK inhibitor (MLV-NLS-JBD) to granule cells of the dentate gyrus for six weeks, evoke an anxiolytic and anti-depressant effect. The key finding was that specific targeting of adult born granule cell JNK was sufficient to switch behaviour to a low anxiety and low depressive state independent of neurogenesis changes [12]. B. Levels of neurogenesis were assessed in Jnk1-/- mice or DJNKI-1-treated mice. Neurogenesis was increased at several levels. There was increased proliferation (BrdU cell number, Ki67-positive cells), survival (decreased numbers of cells positive for cleaved caspase-3) and increased numbers of doublecortin (DCX)positive and BrdU/NeuN-positive cells, representing newly born neurons. Thus global JNK1 inhibition increases hippocampal neurogenesis. However inhibition of JNK solely in immature granule cells using retroviral delivery alleviates mood without increasing neurogenesis, telling us that JNK inhibition evokes separable effects in the hippocampal neurogenic niche, both of which act to lower anxiety and depression.

increased ventral hippocampal output, though this theory requires testing.

From the molecular standpoint, there are several mechanisms whereby JNK could influence the behaviour of new born granule cells leading to changes in the activity of circuits that control mood. New born granule cells exhibit specialized features during a "critical period" from two to six weeks after birth [73]. Within this timeframe, new granule cells show a lower threshold for activation by perforant-path excitatory hippocampal input. This distinguishes them from the resident mature cells that account for $\sim 90 \%$ of dentate neurons and are less easily excited [73, 82]. Increased excitability of immature granule cells is dependent on high expression during the critical period, of the NKCC1 
cotransporter which carries $\mathrm{Cl}^{-}$inwards. High expression of NKCC1 (SLC12A2) results in reversal of the $\mathrm{Cl}^{-}$potential, meaning that upon GABAA receptor activation, $\mathrm{Cl}^{-}$flows outwards, down its concentration gradient and the neurons become depolarized, rather than hyperpolarized [82]. As these neurons mature, NKCC2 (SCL12A1) expression increases and internal $\mathrm{Cl}^{-}$concentrations are restored to lower levels. At this point, granule cells display typical GABA-A responses, i.e. $\mathrm{Cl}^{-}$ ions are driven outwards leading to hypolarization $[83,84]$. JNK has been shown to phosphorylate $\mathrm{NKCC} 1$ in vitro in [85], however whether this alters the activity or expression levels of the cotransporter is not known.

Other key changes that occur to immature granule cells during the critical period include dendritic arborisation and spine formation, together representing increased capacity for synaptic integration. In this regard, we have shown that dendritic field size is increased in immature granule cells in Jnk1 -/- or JNK inhibitor-treated mice [12]. NMDA receptor NR2B subunit expression is also increased during this period and facilitates synaptic plasticity [86]. Whether JNK controls NR2B expression is not known. All in all one can envisage several possible mechanisms whereby pathological activation of JNK (as outlined in Table 1) could alter properties of immature granule cells, either indirectly by altering gene expression, or directly by switching on or off protein function. More precise understanding of what JNK does in immature granule cells to alter mood will be greatly facilitated by phosphoproteomic study and analysis of circuits and gene expression.

\section{WHAT IS KNOWN ABOUT JNK REGULATION IN ANIMAL MODELS OF DEPRESSION?}

Studies in animal models of depression have shown that JNK activity is elevated in the hippocampus and prefrontal cortex (Table 2) [87-93]. For example, chronic treatment with corticosterone [94], strongly activates JNK in the hippocampus [93]. Elevated levels of cortisol in depression signifies impaired feedback regulation of the hypothalamic pituitary adrenal axis [95] and contributes to long lasting synapse loss [35]. Similarly, in chronic variable stress models of depression and in acute stress models (cold followed by rewarming) [87], forced swim and tail suspension tests [91] and immobilization stress [88], JNK is hyper-activated in the hippocampus and prefrontal cortex (Table 2). Significantly, in the social defeat stress model of depression, JNK activity is increased in animals that are susceptible to stress and reduced in animals that are resilient [90], suggesting

Table 2

Regulation of JNK activity in rodent models of depression

\begin{tabular}{|c|c|c|c|c|}
\hline STRESSOR OR DISEASE MODEL & JNK ACTIVITY & BEHAVIOR & CORT & REFERENCES \\
\hline \multicolumn{5}{|l|}{ CHRONIC STRESS } \\
\hline Corticosterone 40 day (mice) & $\uparrow \uparrow \mathrm{HC}$ & $\begin{array}{c}\text { Cognitive deficit reversed } \\
\text { by DJNKI-1 }\end{array}$ & n.a. & [93] \\
\hline Random varied (mice) & $\uparrow \mathrm{HC}$ & n.a. & $\uparrow$ & [89] \\
\hline Random varied + LPS & $\uparrow \uparrow \mathrm{HC}$ & & & \\
\hline Social defeat (mice) & $\begin{array}{l}\uparrow \text { PFC susceptible mice } \\
\downarrow \text { PFC resilient mice }\end{array}$ & $\begin{array}{l}\uparrow \text { Social avoidance } \\
\downarrow \text { Social avoidance }\end{array}$ & n.a. & {$[90]$} \\
\hline \multicolumn{5}{|l|}{ SOCIAL ISOLATION } \\
\hline Social isolation 21 day (rat) & $\downarrow \mathrm{PFC}$ & n.a. & No change & [92] \\
\hline $\begin{array}{l}\text { Social isolation } 21 \text { day + acute } \\
\text { immobilization }\end{array}$ & $\downarrow \mathrm{PFC}$ & n.a. & $\uparrow$ & \\
\hline \multicolumn{4}{|l|}{ ACUTE STRESS } & {$[88]$} \\
\hline Cold (mice) & No effect HC/PFC & Anxiogenic & $\uparrow$ & [87] \\
\hline Cold/rewarming & $\uparrow \uparrow \mathrm{HC} / \mathrm{PFC} / \mathrm{EC}$ & & $\uparrow$ & \\
\hline Forced swim & No effect HC, $\uparrow$ PFC & Depressive & n.a. & [91] \\
\hline Tail suspension & $\uparrow \mathrm{HC} / \mathrm{PFC}$ & Depressive & & \\
\hline Cold (rat) & No effect & n.a. & $\uparrow$ & [92] \\
\hline Immobilization & No effect & n.a. & $\uparrow$ & \\
\hline Immobilization (rat) & $\uparrow \uparrow \mathrm{HC} / \mathrm{PFC}$ & n.a. & $\uparrow$ & [88] \\
\hline LPS & $\uparrow \mathrm{HC}$ & n.a. & $\uparrow$ & [89] \\
\hline
\end{tabular}

In these studies, JNK activity was measured by immunoblotting hippocampus (HC) or prefrontal cortex (PFC) with antibodies detecting active JNK (P-JNK). Chronic and acute stress models are categorized separately. Abbreviations are as follows: Lipopolysaccharide=LPS, Corticosterone $=$ CORT, data not available $=$ n.. . 
that JNK activity predisposes to depression and inhibition of JNK is protective. In contrast to these classic models of depression, exposure of adult rats to 21 days of social isolation (a model for depression and negative symptoms of schizophrenia [96]), does not activate JNK but slightly decreases its activity in the hippocampus and PFC [88, 92] (Table 2). While the stress response was validated in these two studies by showing increased corticosterone levels, the behavioural outcome was not monitored. The reported decrease in JNK activity may therefore represent a protective, adaptive response to social isolation in this relatively short duration isolation model. Finally, cognitive impairment induced by chronic corticosterone administration is reversed by the DJNKI-1 inhibitor [93], while DJNKI-1 also lowers baseline anxiety and depressive behaviour [12]. Together these data provide evidence that JNK is activated in rodent models of depression and that preventing this activation alleviates anxiety and depressive behaviour. Significantly also, reduced JNK activity is associated with resilience to stress.

Genetic components together with environmental influences also contribute to depression and predisposing gene anomalies are actively searched [97]. As of now, no significant genome-wide associations have been found to link the JNK pathway with MDD or bipolar disorder. Although SNPs in the JIP2 (MAPK8IP2) JNK scaffold [98] and in JNK3 (MAPK10) [99] were identified in patient cohorts, these have not shown significant genome-wide associations. Such associations may be obscured by the heterogenous nature of the disease etiology. The first genetic associations with depression are only starting to be identified and improved patient stratification and larger sample sizes will be needed to achieve a comprehensive picture of the genetic background of depression [100].

\section{TARGETING JNK FOR DEPRESSION AND ANXIETY?}

These findings from animal studies, highlight the possibility that targeting of the JNK pathway could provide a new avenue for tackling depression and anxiety. It may even provide benefit for treatment resistant depression. This raises the question as to whether unwanted side effects would be associated with systemic inhibition of JNK. JNKs, by virtue of being kinases, are involved in a variety of functions [55]. Inhibition of JNK is expected to be beneficial for several diseases including cancer, inflammatory diseases, diabetes, neurodegenerative disease, stroke [53], and more recently, depression and anxiety [12, 90]. Indeed, because JNKs are largely silent and activated by stress, there is a rationale to expect minimal side effects. However, cellular stress responses also serve important homeostatic functions. For example JNKs regulate autophagy, albeit oppositely in the periphery and CNS [59, 101]. Also, JNKs 1 and 2 are required for innate immune response signalling [102], and as discussed earlier, JNK isoforms play essential roles during brain development [55]. One can predict therefore that pan-JNK inhibitors would be precluded from use. However, because these important functions of JNKs are largely redundant between isoforms, it is anticipated that isoformspecific inhibitors, or inhibitors of specific functional modules, could be tolerated. Several years of drug development have generated a number of inhibitors against JNK, however a full panel of isoform-specific, or splice variant-specific inhibitors is not yet available [103]. In terms of tolerance, two clinical trials with small molecule ATP-competitive JNK inhibitors have been carried out [103, 104]. These were terminated due to a poor risk/benefit ratio, however these trials did not stratify patients, and it has been proposed that isoform-specific JNK inhibitors would have produced a better outcome [104]. Interestingly however, a small cohort safety trial using DJNKI-1 (XG-102, Brimapitide) reported no drug-related side effects following a single intravenous infusion [105]. Moreover, this inhibitor yielded positive results in the postoperative treatment of ocular inflammation [106], where a single injection showed similar benefit to four applications of dexamethasone over 21 days. This inhibitor is currently undergoing preclinical study for treatment of Alzheimer's disease. Given the recent implications of JNK involvement in depression, it would certainly be of interest to monitor the effects of JNK inhibition on depression and anxiety symptoms in patients, if such trials go ahead.

\section{CONCLUSIONS}

This review highlights recent data that implicates the JNK pathway in the regulation of mood. These early findings are exciting for the following reasons. Firstly, according to current knowledge, there is no overt connection between JNK and the currently used anti-depressant drugs. Therefore, targeting of this mechanism may represent a new avenue for 
treatment development. Secondly, the precise localization of JNK's anxiogenic action to the immature granule cells of the hippocampus provides the possibility for design of selective targeting approaches. In this regard, it will be advantageous to understand more aspects of JNK action in adult born granule cells from in vivo study. While much remains to be understood, we can say that JNK has entered the arena as a kinase that controls anxiety and depressive behaviour in mice, and may contribute to maladaptive changes underlying affective disorders.

\section{ACKNOWLEDGMENTS}

This work was funded by the EU-funded Marie Curie r'BIRTH ITN \# 608346 and by the Academy of Finland project \#310583. We are grateful to the members of the Coffey lab and the rBIRTH consortium for their views and opinions that guided our work on depression and neurogenesis during the course of this network.

\section{REFERENCES}

[1] Whiteford HA, Ferrari AJ, Degenhardt L, Feigin V, Vos T. The global burden of mental, neurological and substance use disorders: An analysis from the Global Burden of Disease Study 2010. PLoS One. 2015;10(2):e0116820.

[2] Covington HE, Vialou V, Nestler EJ. From synapse to nucleus: Novel targets for treating depression. Neuropharmacology. 2010;58(4-5):683-93.

[3] Wainwright SR, Galea LA. The neural plasticity theory of depression: Assessing the roles of adult neurogenesis and PSA-NCAM within the hippocampus. Neural Plast. 2013;2013:805497.

[4] Varidaki A, Mohammad H, Coffey ET. Molecular mechanisms of depression. 1st ed. Frodl T, editor: Elsevier; 2016.

[5] Malberg JE, Eisch AJ, Nestler EJ, Duman RS. Chronic antidepressant treatment increases neurogenesis in adult rat hippocampus. J Neurosci. 2000;20(24):9104-10.

[6] Santarelli L, Saxe M, Gross C, Surget A, Battaglia F, Dulawa S, et al. Requirement of hippocampal neurogenesis for the behavioral effects of antidepressants. Science. 2003;301(5634):805-9.

[7] David DJ, Samuels BA, Rainer Q, Wang JW, Marsteller D, Mendez I, et al. Neurogenesis-dependent and independent effects of fluoxetine in an animal model of anxiety/depression. Neuron. 2009;62(4):479-93.

[8] Surget A, Tanti A, Leonardo ED, Laugeray A, Rainer $\mathrm{Q}$, Touma C, et al. Antidepressants recruit new neurons to improve stress response regulation. Mol Psychiatry. 2011;16(12):1177-88.

[9] Schloesser RJ, Orvoen S, Jimenez DV, Hardy NF, Maynard KR, Sukumar M, et al. Antidepressant-like effects of electroconvulsive seizures require adult neurogenesis in a neuroendocrine model of depression. Brain Stimul. 2015;8(5):862-7.
[10] Bessa JM, Ferreira D, Melo I, Marques F, Cerqueira JJ, Palha JA, et al. The mood-improving actions of antidepressants do not depend on neurogenesis but are associated with neuronal remodeling. Mol Psychiatry. 2009;14(8):764-73, 39.

[11] Marlatt MW, Lucassen PJ, van Praag H. Comparison of neurogenic effects of fluoxetine, duloxetine and running in mice. Brain Res. 2010;1341:93-9.

[12] Mohammad H, Marchisella F, Ortega-Martinez S, Hollos P, Eerola K, Komulainen E, et al. JNK1 controls adult hippocampal neurogenesis and imposes cell-autonomous control of anxiety behaviour from the neurogenic niche. Mol Psychiatry. 2018;23(2):362-74.

[13] Altman J, Das GD. Autoradiographic and histological evidence of postnatal hippocampal neurogenesis in rats. J Comp Neurol. 1965;124(3):319-35.

[14] Spalding KL, Bergmann O, Alkass K, Bernard S, Salehpour M, Huttner HB, et al. Dynamics of hippocampal neurogenesis in adult humans. Cell. 2013;153(6): 1219-27.

[15] Kempermann G. New neurons for 'survival of the fittest'. Nat Rev Neurosci. 2012;13(10):727-36.

[16] Cameron HA, McKay RD. Adult neurogenesis produces a large pool of new granule cells in the dentate gyrus. J Comp Neurol. 2001;435(4):406-17.

[17] Kempermann G, Kuhn HG, Gage FH. More hippocampal neurons in adult mice living in an enriched environment. Nature. 1997;386(6624):493-5.

[18] Bergmann O, Spalding KL, Frisén J. Adult neurogenesis in humans. Cold Spring Harb Perspect Biol. 2015;7(7):a018994.

[19] Kheirbek MA, Drew LJ, Burghardt NS, Costantini DO, Tannenholz L, Ahmari SE, et al. Differential control of learning and anxiety along the dorsoventral axis of the dentate gyrus. Neuron. 2013;77(5):955-68.

[20] Yau SY, Li A, So KF. Involvement of adult hippocampal neurogenesis in learning and forgetting. Neural Plast. 2015;2015:717958.

[21] Revest JM, Dupret D, Koehl M, Funk-Reiter C, Grosjean N, Piazza PV, et al. Adult hippocampal neurogenesis is involved in anxiety-related behaviors. Mol Psychiatry. 2009; 14(10):959-67.

[22] Snyder JS, Glover LR, Sanzone KM, Kamhi JF, Cameron HA. The effects of exercise and stress on the survival and maturation of adult-generated granule cells. Hippocampus. 2009;19(10):898-906.

[23] Wu MV, Hen R. Functional dissociation of adult-born neurons along the dorsoventral axis of the dentate gyrus. Hippocampus. 2014;24(7):751-61.

[24] van Praag H, Christie BR, Sejnowski TJ, Gage FH. Running enhances neurogenesis, learning, and longterm potentiation in mice. Proc Natl Acad Sci U S A. 1999;96(23):13427-31.

[25] Trejo JL, Llorens-Martín MV, Torres-Alemán I. The effects of exercise on spatial learning and anxiety-like behavior are mediated by an IGF-I-dependent mechanism related to hippocampal neurogenesis. Mol Cell Neurosci. 2008;37(2):402-11.

[26] Sahay A, Scobie KN, Hill AS, O'Carroll CM, Kheirbek MA, Burghardt NS, et al. Increasing adult hippocampal neurogenesis is sufficient to improve pattern separation. Nature. 2011;472(7344):466-70.

[27] Vivar C, van Praag H. Running changes the brain: The long and the short of it. Physiology (Bethesda). 2017;32(6):410-24. 
[28] Soumier A, Carter RM, Schoenfeld TJ, Cameron HA. New hippocampal neurons mature rapidly in response to ketamine but are not required for its acute antidepressant effects on neophagia in rats. eNeuro. 2016;3(2).

[29] Costello EJ, Pine DS, Hammen C, March JS, Plotsky PM, Weissman MM, et al. Development and natural history of mood disorders. Biol Psychiatry. 2002;52(6):529-42.

[30] MacMillan S, Szeszko PR, Moore GJ, Madden R, Lorch E, Ivey J, et al. Increased amygdala: Hippocampal volume ratios associated with severity of anxiety in pediatric major depression. J Child Adolesc Psychopharmacol. 2003;13(1):65-73.

[31] Schmaal L, Veltman DJ, van Erp TG, Sämann PG, Frodl $\mathrm{T}$, Jahanshad N, et al. Subcortical brain alterations in major depressive disorder: Findings from the ENIGMA Major Depressive Disorder working group. Mol Psychiatry. 2016;21(6):806-12.

[32] Stockmeier CA, Mahajan GJ, Konick LC, Overholser JC, Jurjus GJ, Meltzer HY, et al. Cellular changes in the postmortem hippocampus in major depression. Biol Psychiatry. 2004;56:640-50.

[33] Hercher C, Turecki G, Mechawar N. Through the looking glass: Examining neuroanatomical evidence for cellular alterations in major depression. J Psychiatr Res. 2009;43(11):947-61.

[34] Soetanto A, Wilson RS, Talbot K, Un A, Schneider JA, Sobiesk M, et al. Association of anxiety and depression with microtubule-associated protein 2- and synaptopodin-immunolabeled dendrite and spine densities in hippocampal CA3 of older humans. Arch Gen Psychiatry. 2010;67:448-57.

[35] Musazzi L, Tornese P, Sala N, Popoli M. Acute or chronic? A stressful question. Trends Neurosci. 2017;40(9):525-35.

[36] Boldrini M, Underwood MD, Hen R, Rosoklija GB, Dwork AJ, John Mann J, et al. Antidepressants increase neural progenitor cells in the human hippocampus. Neuropsychopharmacology. 2009;34(11):2376-89.

[37] Boldrini M, Santiago AN, Hen R, Dwork AJ, Rosoklija GB, Tamir H, et al. Hippocampal granule neuron number and dentate gyrus volume in antidepressant-treated and untreated major depression. Neuropsychopharmacology. 2013;38(6):1068-77.

[38] Kjelstrup KG, Tuvnes FA, Steffenach HA, Murison R, Moser EI, Moser MB. Reduced fear expression after lesions of the ventral hippocampus. Proc Natl Acad Sci U S A. 2002;99(16):10825-30.

[39] Bannerman DM, Deacon RM, Offen S, Friswell J, Grubb M, Rawlins JN. Double dissociation of function within the hippocampus: Spatial memory and hyponeophagia. Behav Neurosci. 2002;116(5):884-901.

[40] Bannerman DM, Rawlins JN, McHugh SB, Deacon RM, Yee BK, Bast T, et al. Regional dissociations within the hippocampus-memory and anxiety. Neurosci Biobehav Rev. 2004;28(3):273-83.

[41] Strange BA, Witter MP, Lein ES, Moser EI. Functional organization of the hippocampal longitudinal axis. Nat Rev Neurosci. 2014;15(10):655-69.

[42] Anacker C, Hen R. Adult hippocampal neurogenesis and cognitive flexibility - linking memory and mood. Nat Rev Neurosci. 2017;18(6):335-46.

[43] Eichenbaum H. Prefrontal-hippocampal interactions in episodic memory. Nat Rev Neurosci. 2017;18(9):547-58.

[44] Nestler EJ, Barrot M, DiLeone RJ, Eisch AJ, Gold SJ, Monteggia LM. Neurobiology of depression. Neuron. 2002;34:13-25.
[45] Deisseroth K. Circuit dynamics of adaptive and maladaptive behaviour. Nature. 2014;505(7483):309-17.

[46] Besnard A, Sahay A. Adult hippocampal neurogenesis, fear generalization, and stress. Neuropsychopharmacology. 2016;41(1):24-44.

[47] Padilla-Coreano N, Bolkan SS, Pierce GM, Blackman DR, Hardin WD, Garcia-Garcia AL, et al. Direct ventral hippocampal-prefrontal input is required for anxiety-related neural activity and behavior. Neuron. 2016;89(4):857-66.

[48] Sousa N, Almeida OF. Disconnection and reconnection: The morphological basis of (mal)adaptation to stress. Trends Neurosci. 2012;35(12):742-51.

[49] Kyriakis JM, Avruch J. Mammalian MAPK signal transduction pathways activated by stress and inflammation: A 10-year update. Physiol Rev. 2012;92(2):689-737.

[50] Karin M, Gallagher E. From JNK to pay dirt: Jun kinases, their biochemistry, physiology and clinical importance. IUBMB Life. 2005;57(4-5):283-95.

[51] Weston CR, Davis RJ. The JNK signal transduction pathway. Curr Opin Cell Biol. 2007;19(2):142-9.

[52] Kuan CY, Yang DD, Samanta Roy DR, Davis RJ, Rakic P, Flavell RA. The Jnk1 and Jnk2 protein kinases are required for regional specific apoptosis during early brain development. Neuron. 1999;22(4):667-76.

[53] Manning AM, Davis RJ. Targeting JNK for therapeutic benefit: From junk to gold? Nat Rev Drug Discov. 2003;2(7):554-65.

[54] Sabio G, Cavanagh-Kyros J, Barrett T, Jung DY, Ko $\mathrm{HJ}$, Ong $\mathrm{H}$, et al. Role of the hypothalamic-pituitarythyroid axis in metabolic regulation by JNK1. Genes Dev. 2010;24(3):256-64.

[55] Coffey ET. Nuclear and cytosolic JNK signalling in neurons. Nat Rev Neurosci. 2014;15(5):285-99.

[56] Coffey ET, Hongisto V, Dickens M, Davis RJ, Courtney MJ. Dual roles for c-Jun N-terminal kinase in developmental and stress responses in cerebellar granule neurons. J Neurosci. 2000;20(20):7602-13.

[57] Coffey ET, Smiciene G, Hongisto V, Cao J, Brecht $\mathrm{S}$, Herdegen $\mathrm{T}$, et al. c-Jun $\mathrm{N}$-terminal protein kinase (JNK) $2 / 3$ is specifically activated by stress, mediating c-Jun activation, in the presence of constitutive JNK1 activity in cerebellar neurons. J Neurosci. 2002;22(11): 4335-45.

[58] Björkblom B, Vainio JC, Hongisto V, Herdegen T, Courtney MJ, Coffey ET. All JNKs can kill, but nuclear localization is critical for neuronal death. J Biol Chem. 2008;283(28):19704-13.

[59] Xu P, Das M, Reilly J, Davis RJ. JNK regulates FoxO-dependent autophagy in neurons. Genes Dev. 2011;25(4):310-22.

[60] Manassero G, Repetto IE, Cobianchi S, Valsecchi V, Bonny C, Rossi F, et al. Role of JNK isoforms in the development of neuropathic pain following sciatic nerve transection in the mouse. Mol Pain. 2012;8:39.

[61] Borsello T, Bonny C. Use of cell-permeable peptides to prevent neuronal degeneration. Trends Mol Med. 2004;10(5):239-44.

[62] Michel-Monigadon D, Bonny C, Hirt L. c-Jun N-terminal kinase pathway inhibition in intracerebral hemorrhage. Cerebrovasc Dis. 2010;29(6):564-70.

[63] Vernia S, Cavanagh-Kyros J, Barrett T, Jung DY, Kim JK, Davis RJ. Diet-induced obesity mediated by the JNK/DIO2 signal transduction pathway. Genes Dev. 2013;27(21):2345-55. 
[64] Solinas G, Becattini B. JNK at the crossroad of obesity, insulin resistance, and cell stress response. Mol Metab. 2017;6(2):174-84.

[65] Yun S, Reynolds RP, Masiulis I, Eisch AJ. Re-evaluating the link between neuropsychiatric disorders and dysregulated adult neurogenesis. Nat Med. 2016;22(11):1239-47.

[66] Dickens M, Rogers JS, Cavanagh J, Raitano A, Xia Z, Halpern JR, et al. A cytoplasmic inhibitor of the JNK signal transduction pathway. Science. 1997;277(5326):693-6.

[67] Frankel AD, Pabo CO. Cellular uptake of the tat protein from human immunodeficiency virus. Cell. 1988;55(6):1189-93.

[68] Kristensen M, Nielsen HM. Cell-penetrating peptides as tools to enhance non-injectable delivery of biopharmaceuticals. Tissue Barriers. 2016;4(2):e1178369.

[69] Bonny C, Oberson A, Negri S, Sauser C, Schorderet DF. Cell-permeable peptide inhibitors of JNK: Novel blockers of beta-cell death. Diabetes. 2001;50(1):77-82.

[70] Barr RK, Kendrick TS, Bogoyevitch MA. Identification of the critical features of a small peptide inhibitor of JNK activity. J Biol Chem. 2002;277(13):10987-97.

[71] Björkblom B, Ostman N, Hongisto V, Komarovski V, Filén JJ, Nyman TA, et al. Constitutively active cytoplasmic c-Jun $\mathrm{N}$-terminal kinase 1 is a dominant regulator of dendritic architecture: Role of microtubule-associated protein 2 as an effector. J Neurosci. 2005;25(27):6350-61.

[72] Komulainen E, Zdrojewska J, Freemantle E, Mohammad H, Kulesskaya N, Deshpande P, et al. JNK1 controls dendritic field size in L2/3 and L5 of the motor cortex, constrains soma size, and influences fine motor coordination. Front Cell Neurosci. 2014;8:272.

[73] Marín-Burgin A, Mongiat LA, Pardi MB, Schinder AF. Unique processing during a period of high excitation/inhibition balance in adult-born neurons. Science. 2012;335(6073):1238-42.

[74] Drew LJ, Kheirbek MA, Luna VM, Denny CA, Cloidt MA, Wu MV, et al. Activation of local inhibitory circuits in the dentate gyrus by adult-born neurons. Hippocampus. 2016;26(6):763-78.

[75] Ikrar T, Guo N, He K, Besnard A, Levinson S, Hill A, et al. Adult neurogenesis modifies excitability of the dentate gyrus. Front Neural Circuits. 2013;7:204.

[76] Lacefield CO, Itskov V, Reardon T, Hen R, Gordon JA. Effects of adult-generated granule cells on coordinated network activity in the dentate gyrus. Hippocampus. 2012;22(1):106-16.

[77] Jin J, Maren S. Prefrontal-hippocampal interactions in memory and emotion. Front Syst Neurosci. 2015; 9:170.

[78] Richardson MP, Strange BA, Dolan RJ. Encoding of emotional memories depends on amygdala and hippocampus and their interactions. Nat Neurosci. 2004;7(3): 278-85.

[79] Britt JP, Benaliouad F, McDevitt RA, Stuber GD, Wise RA, Bonci A. Synaptic and behavioral profile of multiple glutamatergic inputs to the nucleus accumbens. Neuron. 2012;76(4):790-803.

[80] Wolff M, Alcaraz F, Marchand AR, Coutureau E. Functional heterogeneity of the limbic thalamus: From hippocampal to cortical functions. Neurosci Biobehav Rev. 2015;54:120-30.

[81] Bagot RC, Parise EM, Peña CJ, Zhang HX, Maze I, Chaudhury D, et al. Ventral hippocampal afferents to the nucleus accumbens regulate susceptibility to depression. Nat Commun. 2015;6:7062.
[82] Toni N, Schinder AF. Maturation and functional integration of new granule cells into the adult hippocampus. Cold Spring Harb Perspect Biol. 2015;8(1):a018903.

[83] Ge S, Goh EL, Sailor KA, Kitabatake Y, Ming GL, Song $\mathrm{H}$. GABA regulates synaptic integration of newly generated neurons in the adult brain. Nature. 2006;439(7076): 589-93.

[84] Karten YJ, Jones MA, Jeurling SI, Cameron HA GABAergic signaling in young granule cells in the adult rat and mouse dentate gyrus. Hippocampus. 2006;16(3): 312-20.

[85] Klein JD, Lamitina ST, O'Neill WC. JNK is a volume-sensitive kinase that phosphorylates the Na-K2Cl cotransporter in vitro. Am J Physiol. 1999;277(3 Pt 1):C425-31.

[86] Ge S, Yang CH, Hsu KS, Ming GL, Song H. A critical period for enhanced synaptic plasticity in newly generated neurons of the adult brain. Neuron. 2007;54(4): 559-66.

[87] Zheng G, Chen Y, Zhang X, Cai T, Liu M, Zhao F, et al. Acute cold exposure and rewarming enhanced spatial memory and activated the MAPK cascades in the rat brain. Brain Res. 2008;1239:171-80.

[88] Adzic M, Djordjevic J, Djordjevic A, Niciforovic A, Demonacos C, Radojcic M, et al. Acute or chronic stress induce cell compartment-specific phosphorylation of glucocorticoid receptor and alter its transcriptional activity in Wistar rat brain. J Endocrinol. 2009;202(1):87-97.

[89] Espinosa-Oliva AM, de Pablos RM, Villarán RF, Argüelles $\mathrm{S}$, Venero JL, Machado A, et al. Stress is critical for LPSinduced activation of microglia and damage in the rat hippocampus. Neurobiol Aging. 2011;32(1):85-102.

[90] Rosa SG, Pesarico AP, Nogueira CW. m-Trifluoromethyldiphenyl diselenide promotes resilience to social avoidance induced by social defeat stress in mice: Contribution of opioid receptors and MAPKs. Prog Neuropsychopharmacol Biol Psychiatry. 2017.

[91] Galeotti N, Ghelardini C. Regionally selective activation and differential regulation of ERK, JNK and p38 MAP kinase signalling pathway by protein kinase $\mathrm{C}$ in mood modulation. Int $\mathrm{J}$ Neuropsychopharmacol. 2012;15(6):781-93.

[92] Filipović D, Zlatković J, Pavićević I, Mandić L, Demajo M. Chronic isolation stress compromises JNK/c-Jun signaling in rat brain. $\mathrm{J}$ Neural Transm (Vienna). 2012;119(11):1275-84

[93] Solas M, Gerenu G, Gil-Bea FJ, Ramírez MJ. Mineralocorticoid receptor activation induces insulin resistance through c-Jun $\mathrm{N}$-terminal kinases in response to chronic corticosterone: Cognitive implications. J Neuroendocrinol. 2013;25(4):350-6.

[94] Krishnan V, Nestler EJ. Animal models of depression: Molecular perspectives. Curr Top Behav Neurosci. 2011;7:121-47.

[95] Binder EB, Künzel HE, Nickel T, Kern N, Pfennig A, Majer M, et al. HPA-axis regulation at in-patient admission is associated with antidepressant therapy outcome in male but not in female depressed patients. Psychoneuroendocrinology. 2009;34(1):99-109.

[96] Wilson CA, Koenig JI. Social interaction and social withdrawal in rodents as readouts for investigating the negative symptoms of schizophrenia. Eur Neuropsychopharmacol. 2014;24(5):759-73.

[97] Lohoff FW. Overview of the genetics of major depressive disorder. Curr Psychiatry Rep. 2010;12(6):539-46. 
[98] Severinsen JE, Bjarkam CR, Kiaer-Larsen S, Olsen IM, Nielsen MM, Blechingberg J, et al. Evidence implicating BRD1 with brain development and susceptibility to both schizophrenia and bipolar affective disorder. Mol Psychiatry. 2006;11(12):1126-38.

[99] Group PGCBDW. Large-scale genome-wide association analysis of bipolar disorder identifies a new susceptibility locus near ODZ4. Nat Genet. 2011;43(10):977-83.

[100] Mullins N, Lewis CM. Genetics of depression: Progress at last. Curr Psychiatry Rep. 2017;19(8):43.

[101] Wei Y, Sinha S, Levine B. Dual role of JNK1-mediated phosphorylation of Bcl-2 in autophagy and apoptosis regulation. Autophagy. 2008;4(7):949-51.

[102] Zhang B, Li M, Chen L, Yang K, Shan Y, Zhu L, et al. The TAK1-JNK cascade is required for IRF3 function in the innate immune response. Cell Res. 2009;19(4):412-28.

[103] Gehringer M, Muth F, Koch P, Laufer SA. c-Jun Nterminal kinase inhibitors: A patent review (2010 - 2014). Expert Opin Ther Pat. 2015;25(8):849-72.
[104] Messoussi A, Feneyrolles C, Bros A, Deroide A, DaydéCazals B, Chevé $\mathrm{G}$, et al. Recent progress in the design, study, and development of c-Jun N-terminal kinase inhibitors as anticancer agents. Chem Biol. 2014;21(11):1433-43.

[105] Deloche C, Lopez-Lazaro L, Mouz S, Perino J, Abadie C, Combette JM. XG-102 administered to healthy male volunteers as a single intravenous infusion: A randomized, double-blind, placebo-controlled, dose-escalating study. Pharmacol Res Perspect. 2014;2(1):e00020.

[106] Chiquet C, Aptel F, Creuzot-Garcher C, Berrod JP, Kodjikian L, Massin P, et al. Postoperative ocular inflammation: A single subconjunctival injection of XG-102 compared to dexamethasone drops in a randomized trial. Am J Ophthalmol. 2017;174:76-84.

[107] Tararuk T, Ostman N, Li W, Björkblom B, Padzik A, Zdrojewska J, et al. JNK1 phosphorylation of SCG10 determines microtubule dynamics and axodendritic length. J Cell Biol. 2006;173(2):265-77. 